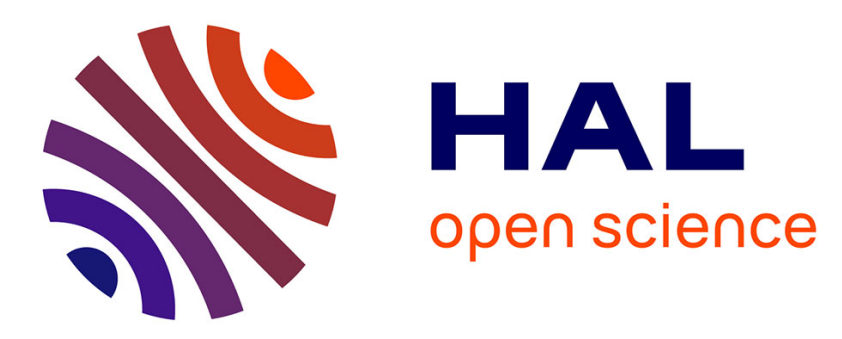

\title{
Granular fingering as a mechanism for ridge formation in debris avalanche deposits: Laboratory experiments and implications for Tutupaca volcano, Peru
}

P. Valderrama, Olivier Roche, P. Samaniego, Benjamin van Wyk de Vries, G. Araujo

\section{To cite this version:}

P. Valderrama, Olivier Roche, P. Samaniego, Benjamin van Wyk de Vries, G. Araujo. Granular fingering as a mechanism for ridge formation in debris avalanche deposits: Laboratory experiments and implications for Tutupaca volcano, Peru. Journal of Volcanology and Geothermal Research, 2018, 349, pp.409-418. 10.1016/j.jvolgeores.2017.12.004 . hal-01677525

\section{HAL Id: hal-01677525 \\ https://hal.uca.fr/hal-01677525}

Submitted on 2 Oct 2018

HAL is a multi-disciplinary open access archive for the deposit and dissemination of scientific research documents, whether they are published or not. The documents may come from teaching and research institutions in France or abroad, or from public or private research centers.
L'archive ouverte pluridisciplinaire HAL, est destinée au dépôt et à la diffusion de documents scientifiques de niveau recherche, publiés ou non, émanant des établissements d'enseignement et de recherche français ou étrangers, des laboratoires publics ou privés. 


\title{
Granular fingering as a mechanism for ridge formation in debris avalanche deposits: Laboratory experiments and implications for Tutupaca volcano, Peru
}

\author{
P. Valderrama ${ }^{\mathrm{a}, \mathrm{b}}$, O. Roche ${ }^{\mathrm{b}, *}$, P. Samaniego ${ }^{\mathrm{b}}$, B. van Wyk des Vries ${ }^{\mathrm{b}}$, G. Araujo $^{\mathrm{a}}$ \\ a Observatorio Vulcanológico del INGEMMET, Av. Canada 1470, San Borja, Lima, Peru \\ ${ }^{\mathrm{b}}$ Université Clermont Auvergne, CNRS, IRD, OPGC, Laboratoire Magmas et Volcans, F-63000 Clermont-Ferrand, France
}

\begin{abstract}
The origin of subparallel, regularly-spaced longitudinal ridges often observed at the surface of volcanic and other rock avalanche deposits remains unclear. We addressed this issue through analogue laboratory experiments on flows of bi-disperse granular mixtures, because this type of flow is known to exhibit granular fingering that causes elongated structures resembling the ridges observed in nature. We considered four different mixtures of fine (300-400 $\mu \mathrm{m})$ glass beads and coarse $(600-710 \mu \mathrm{m}$ to $900-1000 \mu \mathrm{m})$ angular crushed fruit stones, with particle size ratios of 1.9-2.7 and mass fractions of the coarse component of 5-50 wt\%. The coarse particles segregated at the flow surface and accumulated at the front where flow instabilities with a well-defined wavelength grew. These formed granular fingers made of coarse-rich static margins delimiting fines-rich central channels. Coalescence of adjacent finger margins created regular spaced longitudinal ridges, which became topographic highs as finger channels drained at final emplacement stages. Three distinct deposit morphologies were observed: 1 ) Joined fingers with ridges were formed at low $(\leq 1.9)$ size ratio and moderate $(10-20 \mathrm{wt} \%)$ coarse fraction whereas 2) separate fingers or 3 ) poorly developed fingers, forming series of frontal lobes, were created at larger size ratios and/or higher coarse contents. Similar ridges and lobes are observed at the debris avalanche deposits of Tutupaca volcano, Peru, suggesting that the processes operating in the experiments can also occur in nature. This implies that volcanic (and non-volcanic) debris avalanches can behave as granular flows, which has important implications for interpretation of deposits and for modeling. Such behaviour may be acquired as the collapsing material disaggregates and forms a granular mixture composed by a right grain size distribution in which particle segregation can occur. Limited fragmentation and block sliding, or grain size distributions inappropriate for promoting granular fingering can explain why ridges are absent in many deposits.
\end{abstract}

Keywords: Debris avalanche Granular fingering Ridge Granular flow Analogue experiments

\section{Introduction}

Debris avalanches and landslides occur in many volcanic and nonvolcanic contexts and represent major geological hazards (van Wyk de Vries and Davies, 2015). The kinematics and dynamics of these gravitational mass flows can be studied through analysis of the architecture and the surface structures of their deposits. The geological literature reports various surface structures, including hummocks (Clavero et al., 2002; Paguican et al., 2012) and elongated structures termed either furrows (Belousov et al., 1999), flow bands (Dufresne and Davies, 2009) or ridges (or longitudinal ridges, Samaniego et al., 2015; Valderrama et al., 2016). The elongated structures, hereafter designated as ridges, are strictly linear to slightly curved, often form swarms of subparallel and regularly-spaced lineations, and have typical lengths of several hundred

\footnotetext{
* Corresponding author.

E-mail address: olivier.roche@uca.fr (O. Roche).
}

of meters. Examples have been described in volcanic debris avalanche deposits (Fig. 1) such as at Shiveluch (Belousov et al., 1999) and Socompa (van Wyk de Vries et al., 2001), and in landslides in nonvolcanic environments such as the Sherman Glacier rock-avalanche, Alaska (Dufresne and Davies, 2009) or the Tschirgant rock-avalanche, Austria (Dufresne et al., 2016). Similar features have also been described in extraterrestrial contexts (Luchitta, 1978).

Samaniego et al. (2015) and Valderrama et al. (2016) have reported very well preserved ridges in the last debris avalanche deposit $(218 \pm$ 14 aBP) of Tutupaca volcano in southern Peru (Fig. 1). Valderrama et al. (2016) concluded that these ridges may give fundamental insights into the dynamics of the debris avalanche, as they could be the consequence of granular fingering, a physical process observed in polydisperse granular flows (Pouliquen et al., 1997; Pouliquen and Vallance, 1999; Malloggi et al., 2006; Woodhouse et al., 2012; Gray et al., 2015). The present work is aimed at further investigating granular fingering in order to discuss the mechanisms of debris avalanches. It is 

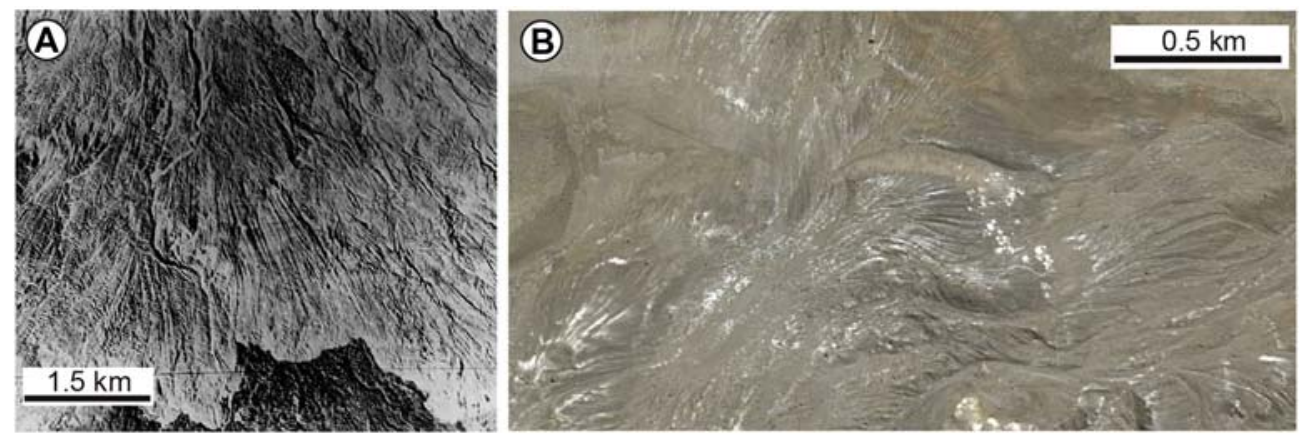

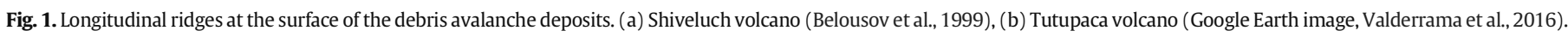

worth noting that granular fingering has received little attention since its discovery by Pouliquen et al. (1997) and its detailed mechanisms have yet to be fully investigated. For this reason we made new experiments on granular flows using bi-disperse mixtures as in previous similar studies but considering systematically different grain size ratios and concentrations of the granular components. We report the different stages of granular segregation and fingering and discuss how the grain size ratio influences the shape and the surface structures of the flow deposits. Finally, we show that the structures in experiments share many similarities with those described at the Tutupaca volcano debris avalanche, which permits us to interpret the emplacement mechanisms of this volcanic mass flow.

\section{Fingering: a fundamental process in granular flows}

Granular fingering was first reported by Pouliquen et al. (1997) from a series of laboratory experiments, and it was further investigated by Pouliquen and Vallance (1999), Malloggi et al. (2006), Woodhouse et al. (2012) and Gray et al. (2015). In their seminal studies Pouliquen et al. (1997) and Pouliquen and Vallance (1999) carried out experiments on bi-disperse granular flows on rough inclines (Fig. 2). They used mixtures of small sub-spherical glass beads of diameter of 500 $\mu \mathrm{m}$ and of large particles made of angular crushed fruit stones of size of $570 \mu \mathrm{m}$ or $1200 \mu \mathrm{m}$, with volume concentrations of the coarse component of 5-8\%. Flows were generated in a channel, $1.5-2 \mathrm{~m}$-long and

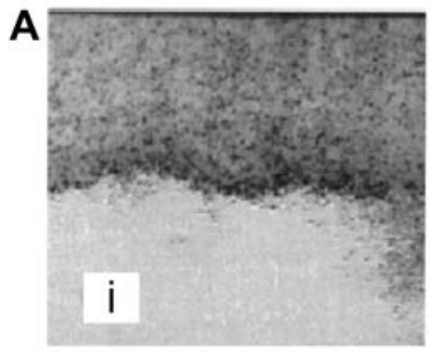

B
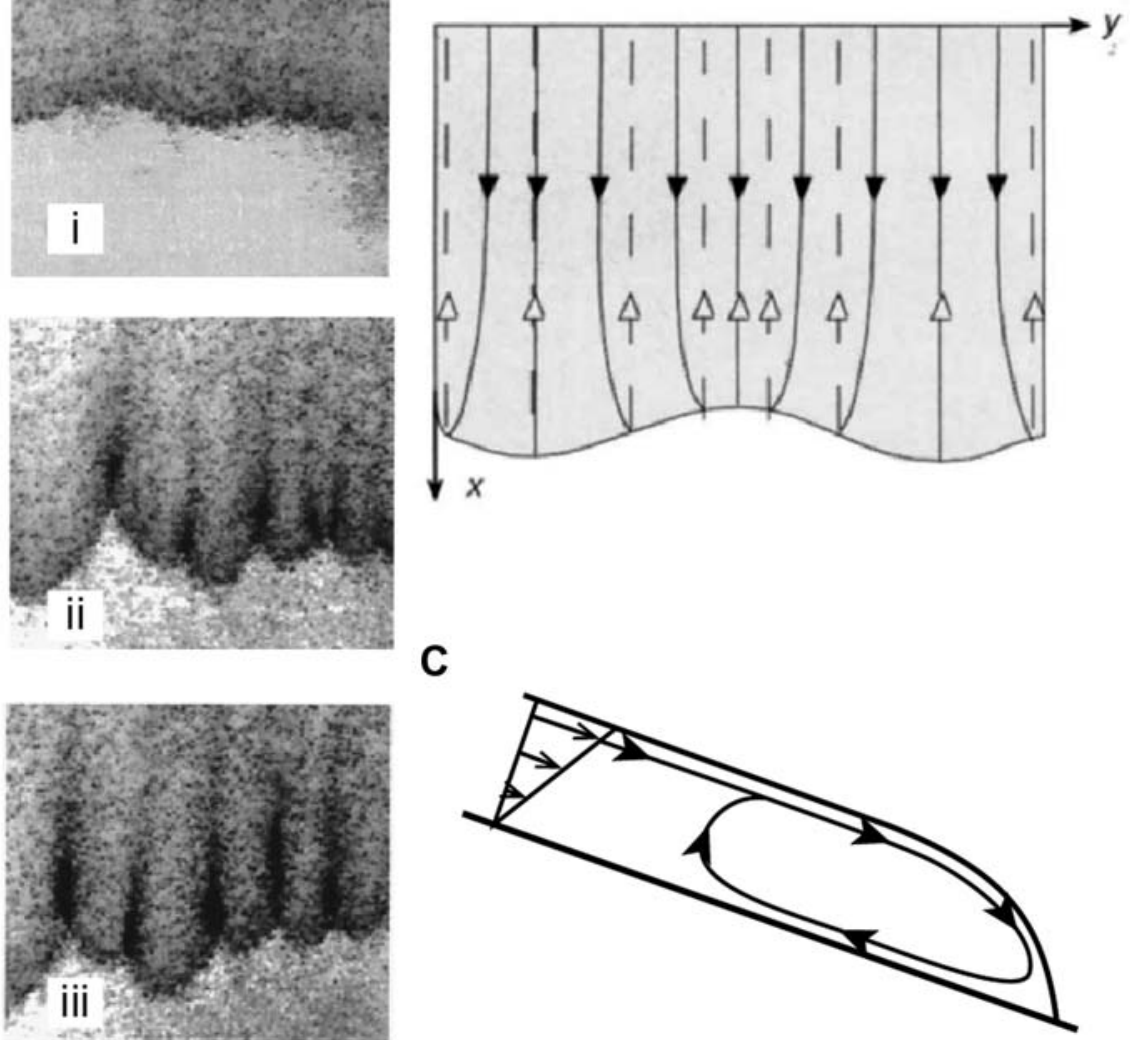

C

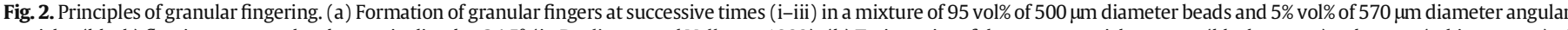

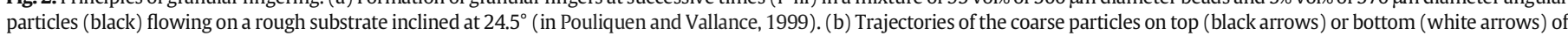
the granular flow (in Pouliquen et al., 1997). (c) Sketch of the recirculation of the coarse particles at the flow front (from Pouliquen et al., 1997). 
$0.7 \mathrm{~m}$-wide, whose rigid substrate was made rough by gluing the same particles as the fine granular flow component. The bi-disperse mixtures were released from a reservoir with constant gate opening of $0.4-0.7 \mathrm{~cm}$, hence generating flows of nearly constant thickness down the incline. Granular fingering arose as a consequence of particle segregation. The larger particles segregated at the surface of the flows because of the combined effects of percolation of the small beads through the shearing granular network and of squeeze expulsion of the large components. Once at the flow surface, these large particles travelled faster than the rest of the flowing mass, because the flow velocity across the flow depth increased upwards, and as a consequence they concentrated at the flow front. The large particles were deflected along the steepest surface slope at the flow front and accumulated to form local instabilities characterized by emerging frontal lobes with static lateral margins immediately behind. Large friction associated to the sliding of these irregular-shaped particles helped amplifying the frontal instabilities, which progressively acquired the shape of granular fingers of nearly constant width and with well-defined static coarsegrained margins that merged to form well-defined linear structures. Segregation and granular fingering were favoured by recirculation of the coarse grains at the flow front as particles that reached the flow base were reinjected upwards to the free surface where segregation acted again (Fig. 2). This recirculation process was later investigated in detail in large-scale experiments by Johnson et al. (2012) and theoretically by Gray and Kokelaar (2010). Granular fingering was also addressed theoretically by Woodhouse et al. (2012) and Gray et al. (2015). Pouliquen and Vallance (1999) and Malloggi et al. (2006) reported that granular fingering can occur as well in subaqueous flows.

A key result of the studies is that the merged coarse-grained margins of granular fingers are longitudinal structures similar to the ridges observed at the surface of many debris avalanche deposits. These studies, however, focused on the morphology of the flowing granular masses and did not consider their deposits. Furthermore, they did not investigate granular fingering systematically as a function of the size ratio of the granular components and they considered only very low volume fractions of the coarse grains. In this context, the aim of our experimental study is to further investigate granular fingering by taking into account wider ranges of grain size ratio and of proportion of the components of bi-disperse mixtures. Also, we investigated the flow kinematics as well as the morphology of the deposits, which can be compared to natural cases.

\section{Experimental procedure}

\subsection{Experimental device and particles}

The experimental device consisted of a $1.45 \times 0.45$ m inclined channel connected to a reservoir from which granular mixtures were released to generate flows (Fig. 3). The reservoir was equipped with a double gate system to ensure a constant mixture outflow rate. The aperture of the back door was set to $1.5 \mathrm{~cm}$ for all experiments while the front door was entirely removed to release the particles. The channel was made rough by gluing $300-400 \mu \mathrm{m}$ subspherical glass particles

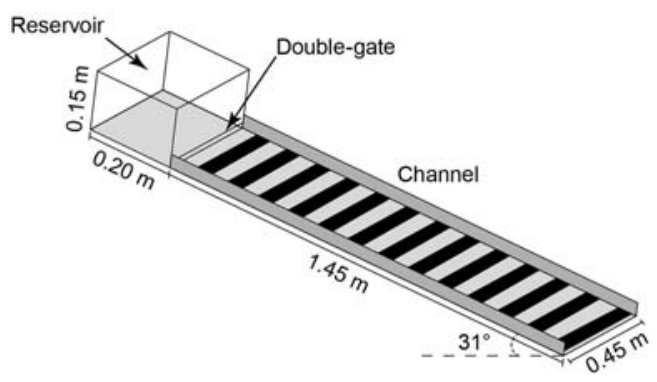

Fig. 3. Schematic view of the experimental device. onto an adhesive sheet that laid on the channel base. As some particles could be entrained by the flows, the base was replaced every ten experiments to ensure a consistent roughness. The experiments were filmed with a high resolution $(1920 \times 1080$ pixels $)$ video camera in order to investigate the flow kinematics and the segregation processes. Transversal black marks were placed beneath the non-opaque rough base every $5 \mathrm{~cm}$ to allow for measurement of the flow front propagation.

Experiments were done with four bi-disperse mixtures of subspherical glass beads with a grain size of 300-400 $\mu \mathrm{m}$ (same as for the rough channel base) and of coarse angular particles (crushed fruit stones, cf. Pouliquen et al., 1997; Pouliquen and Vallance, 1999) with grain size ranges from 600 to $710 \mu \mathrm{m}$ up to $900-1000 \mu \mathrm{m}$ (Table 1 ). The mass fraction of the coarse component in the mixtures varied from 5 to $50 \%$. Before each experiment, the bi-disperse material was stirred by hand gently and thoroughly to generate mixtures as homogeneous as possible. The fine and coarse components of the mixtures represented respectively the matrix and the largest blocks of natural materials.

\subsection{Photogrammetry of the deposits}

After each experiment at least 14 photographs were taken with the high resolution camera from different angles for photogrammetry in order to obtain digital elevation models (DEM) of the flow deposits. A white halogen light was used to make stand out the detailed shapes and structures of the deposits. Photogrammetry was processed using the software Agisoft Photoscan Professional Edition version 1.1.6 for Mac (see Smith et al., 2016, for details on the method). In order to improve the DEM resolution, we created a reference system with a minimum unit size of $0.05 \mathrm{~mm}$, which was calibrated using the coordinates of 7 fixed points previously marked on the experimental device. Data processing permitted us to obtain DEMs of the experimental deposits with a resolution of $0.5 \mathrm{~mm}$ (Fig. 4). The DEMs were then used to retrieve cross-sections of the deposits, which were compared to measurements made in situ with a ruler.

\section{Results}

In this section we first present preliminary experiments that permitted us to define the parameters we chose to investigate granular fingering in detail. Then, we report the flow kinematic data as well as the morphological characteristics of the deposits, including the final length, the thickness and the width of the fingers, and the distance between the axis of the fingers.

\subsection{Preliminary tests}

We tested different mixtures with various grain sizes and proportions of particles. We first used mixtures of the glass beads (300-400 $\mu \mathrm{m})$ and the smaller coarse particles (600-710\%), the latter at concentrations of 5 to $50 \mathrm{wt} \%$ (Table 1). On the basis of this first series of experiments, we concluded that the flows experienced well-defined granular segregation and fingering for coarse particle concentrations of 5 to 20 wt\%. Then, experiments were made with larger coarse particles sizes at concentrations of 5 to $20 \mathrm{wt} \%$ (Table 1). Experiments with a given mixture were repeated at least three times and showed good reproducibility.

The inclination of the channel and the volume of material released from the reservoir were set according to the experiments that generated the most elongated deposits but shorter than the channel length. We concluded that the most appropriate slope angle and material mass were $31^{\circ}$ and $1 \mathrm{~kg}$, respectively. At lower angles the flows stopped too close to the gate while at higher angles they left the channel. The mass (and so the volume) of material controlled fundamentally the length of the deposits. Videos of the experiments revealed that the flow kinematics was characterized by three stages of emplacement: particle 
Table 1

Granular bi-disperse mixtures used in experiments. Grain size ranges were obtained through particle sieving.

\begin{tabular}{|c|c|c|c|c|}
\hline & Fine particles (glass beads) & Coarse particles (crushed fruit stones) & Mean size ratio & Mass fraction of large particles (\%) \\
\hline Mixture 1 & $300-400 \mu \mathrm{m}$ & $600-710 \mu \mathrm{m}$ & 1.9 & $5,10,15,20,30,40,50$ \\
\hline Mixture 2 & $300-400 \mu \mathrm{m}$ & $710-800 \mu \mathrm{m}$ & 2.1 & $5,10,15,20$ \\
\hline Mixture 3 & $300-400 \mu \mathrm{m}$ & $800-900 \mu \mathrm{m}$ & 2.4 & $5,10,15,20$ \\
\hline Mixture 4 & $300-400 \mu \mathrm{m}$ & $900-1000 \mu \mathrm{m}$ & 2.7 & $5,10,15,20$ \\
\hline
\end{tabular}

segregation, then accumulation of the coarse particles at flow front, and finally granular fingering (Fig. 5). This is described in detail below (see Fig. 6).

\subsection{Flow kinematics}

\subsubsection{Stage 1: segregation}

Particle segregation occurred as soon as the granular mixture propagated downslope after gate opening (Fig. 6). Most of the small particles percolated downwards while the coarse particles moved to the top of the flow and concentrated at the front. This stage was characterized by the highest flow front velocity, which was about $40 \mathrm{~cm} / \mathrm{s}$ and was independent on both the coarse particle size and concentration (Fig. 7). It appeared that at this stage, the front velocity was controlled by the slope angle. The distance travelled by the flows, however, tended to decrease with the coarse particles content (Fig. 7).

\subsubsection{Stage 2: accumulation of coarse particles at flow front}

During this stage most of the coarse particles accumulated at the flow front (Fig. 6). This caused instabilities (cf. Pouliquen et al., 1997) and the flow front slowed down (or even stopped for a short duration in some experiments) while the rest of mass upstream propagated at the initial velocity acquired at Stage 1 . In consequence, the front was overtaken by the material behind, which caused a surface wave which favoured flow propagation downslope. The front instabilities then grew to form emerging fingers. After a couple of seconds, about $80 \%$ of the coarse particles had accumulated at the front (Fig. $6, t=2.06 \mathrm{~s}$ ).

Detailed information on the times and distances at which this second stage began and ended for the different mixtures is presented in Figs. 6 and 7. For mixtures with $\leq 20 \mathrm{wt} \%$ of coarse particles stage 2 began at distances of $60-80 \mathrm{~cm}$ from the reservoir and at times of 2-3 s after release, except for mixtures with 900-1000 $\mu \mathrm{m}$ coarse particles for which these distances and times were rather 75-95 cm and 3-3.5 s, respectively. During this stage the distance travelled was fairly short, typically $5-15 \mathrm{~cm}$, and the flows propagated at relatively slow velocities of $5-15 \mathrm{~cm} / \mathrm{s}$. The complementary experiments with $\geq 30 \mathrm{wt} \%$ of 600-710 $\mu \mathrm{m}$ coarse particles, however, revealed that the distance travelled was up to $70 \mathrm{~cm}$ at concentration of $50 \mathrm{wt} \%$.

\subsubsection{Stage 3: fingering}

The final stage of propagation was characterized by granular fingering and a significant decrease of the velocity of the flowing mass (Figs. 6 and 7). The fingers formed as a consequence of particle segregation, accumulation of coarse particles at the flow front and formation of local instabilities, which grew to form fines-rich channels bordered by coarse-rich static margins (cf. Pouliquen et al., 1997). Accumulation of the coarse particles at the flow front, which began during stage 2 and decreased the velocity of the moving mass, further operated during this last stage and caused even lower propagation velocities of about $2-3 \mathrm{~cm} / \mathrm{s}$ until the granular mass halted (Fig. 7). Note that some low amplitude surface waves that arose in the proximal area provided material that concentrated further downstream in the channels (see Fig. 6 at $t$ $>6.16 \mathrm{~s}$ ). The fingers delimited by the stable margins had a constant width, and the flowing granular mass mainly composed of small particles in the central channel eventually drained once material supply from the reservoir was no longer available. The inner part of the static margins could be eroded by the flow in the central channels.

An important result of our experiments is that the fingers were either merged or separated depending on the nature of the granular mixtures (Fig. 8). Well-defined long fingers were merged, and their joint margins then formed longitudinal ridges, when the grain size difference between the two components was small (i.e. with 600-710 $\mu$ m coarse particles) and at moderate coarse concentrations of 10-20 wt\% (lower concentrations of $5 \mathrm{wt} \%$ did not promote enough segregation for allowing emergence of fingering). With these conditions the mean distance travelled by the fingers was typically $20-30 \mathrm{~cm}$ (Fig. 6). Note that at concentrations of $20 \mathrm{wt} \%$ the range of travel distance was fairly large and that some fingers propagated out of the channel (Fig. 8). In contrast,
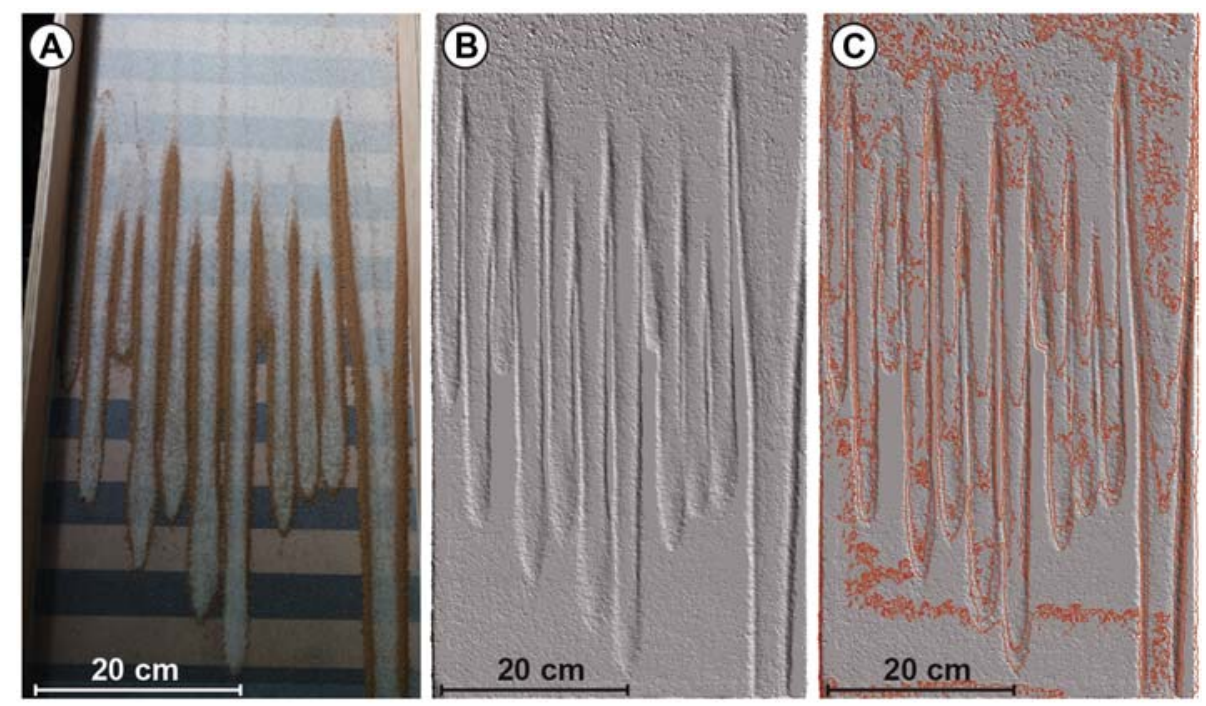

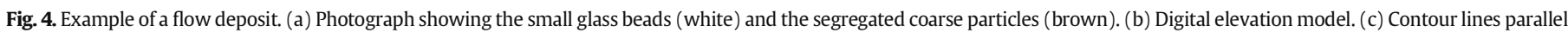
to the inclined plane. (For interpretation of the references to colour in this figure legend, the reader is referred to the web version of this article.) 


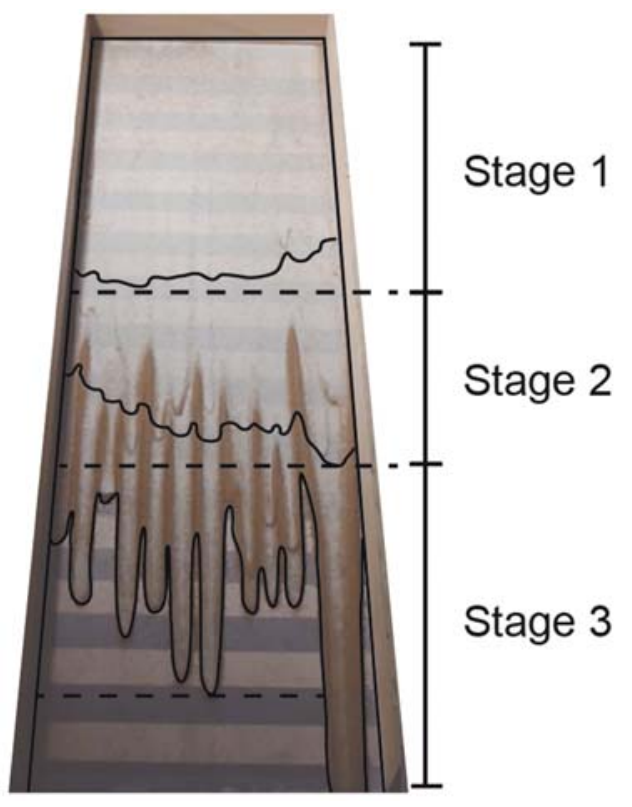

Fig. 5. Contours of the flow front at end of the three stages of emplacement. Stage 1: segregation of the particles. Stage 2: accumulation of the coarse particles at flow front. Stage 3: granular fingering.

in other mixtures the fingers were either separated and/or poorly developed and then rather formed series of frontal lobes. In particular, welldefined separated fingers formed in mixtures 3 and 4 with coarse components of $800-900 \mu \mathrm{m}$ at $10 \mathrm{wt} \%$ and of $900-1000 \mu \mathrm{m}$ at $20 \mathrm{wt} \%$ (Fig. 8).

\subsection{Morphology of the deposits}

Photogrammetric images of the three types of deposit morphology are shown in Fig. 9. They reveal that the fingers consisted of a frontal lobe and of a central channel bordered by lateral levees, which became topographic highs as the granular material in the channel drained at late stages. In case of joined fingers the levees either merged completely or incompletely, hence leading to one large or two small local topographic highs, and they thus formed the longitudinal ridges. When the local instabilities did not lead to fully developed fingers the granular material accumulated at the front and formed series of merged, and sometimes superposed lobes thicker than the rest of the deposit upstream.

The detailed morphological data of the fingers are given in Fig. 10. Note that we measured all fingers even when these were poorly developed and rather resembled lobes (see Fig. 8). We recall that the percentages we give below are those of the coarse particles concentration in the mixtures. The joint fingers were the longest for mixture 1 with the smallest $(600-710 \mu \mathrm{m})$ coarse particles. Their mean length increased from $35 \mathrm{~cm}$ at $5 \mathrm{wt} \%$ up to $63 \mathrm{~cm}$ at $20 \mathrm{wt} \%$, and complementary experiments at higher concentrations revealed lengths of $\sim 50-70 \mathrm{~cm}$. Notice that the ranges of length were quite large, typically $\sim 30-50 \mathrm{~cm}$. For other mixtures the joint fingers were significantly shorter as their mean length was $\sim 10-30 \mathrm{~cm}$. For mixtures 2 and 3, however, one or two long (up to $\sim 50 \mathrm{~cm}$ ) fingers commonly formed, causing length ranges as large as for mixture 1 .

The separate fingers formed in mixtures 3 (at $10 \mathrm{wt} \%$ ) and 4 (at $20 \mathrm{wt} \%$ ) had significantly longer mean lengths of $37 \mathrm{~cm}$ and $39 \mathrm{~cm}$, respectively. The mean thickness of the fingers was $\sim 2-6 \mathrm{~mm}$ and varied very little in a given experiment except at very high coarse particle content of $50 \mathrm{wt} \%$ in mixture 1 . It increases clearly with the coarse concentration in mixture 1 at $\geq 15 \mathrm{wt} \%$ and in mixture 2 . The long separate fingers in mixture 4 at $20 \mathrm{wt} \%$ were thinner $(\sim 1.5 \mathrm{~mm})$ than in other cases. The mean width of the fingers was $3.5-5.5 \mathrm{~cm}$ for mixtures at $5-20 \mathrm{wt} \%$ (with ranges of values of $\sim 2-3 \mathrm{~cm}$ ). It increased fairly clearly with the coarse particles content and was about the same for the different mixtures at same concentrations. Complementary experiments with mixture 1 showed that the width increased up to $\sim \mathrm{cm}$ at $50 \mathrm{wt} \%$. The widths of the separate fingers were in the trends defined by those of the joint fingers. Finally, the distance between the axis of the joint fingers was in general close to the width, as imposed by the geometrical configuration. For the separate fingers, however, this distance was longer that the finger width.
Stage 1 (segregation)
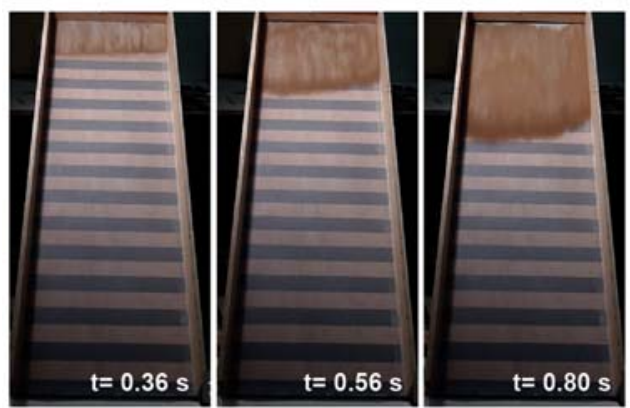

Stage 2 (accumulation)

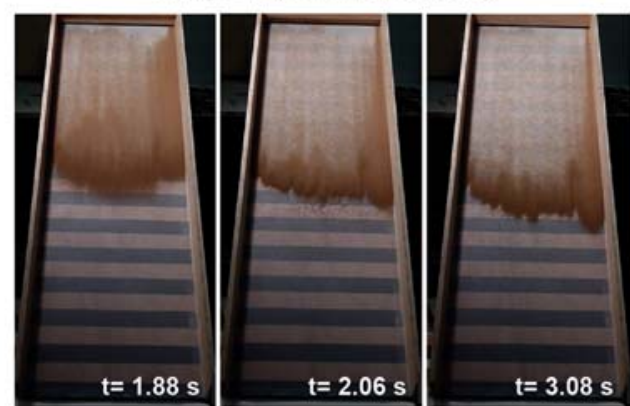

Stage 3 (fingering)
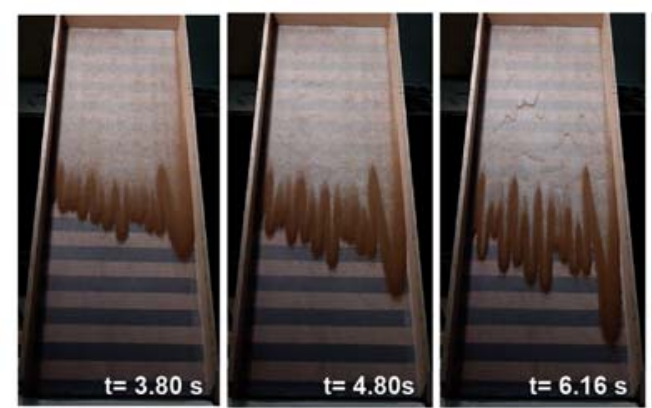
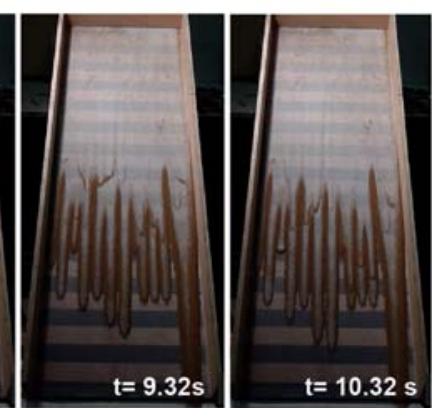

Fig. 6. Snapshots showing the stages of flow propagation for a mixture of 300-400 $\mu \mathrm{m}$ glass beads and $15 \mathrm{wt} \%$ of $600-710 \mu \mathrm{m}$ coarse particles. Final deposit at $t=10.32 \mathrm{~s}$. 

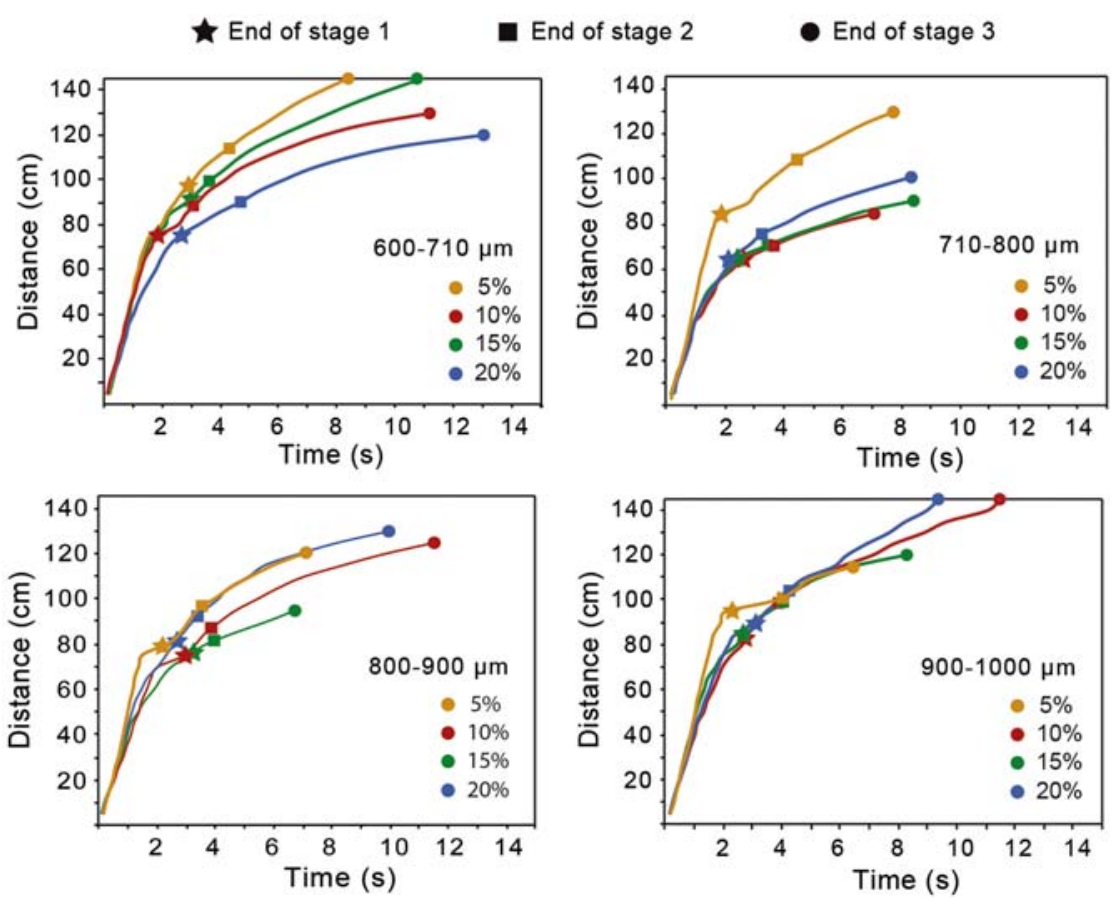

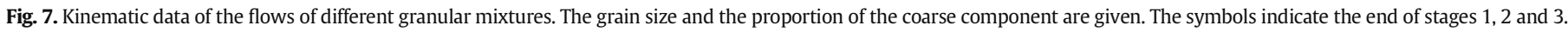
Note that some flow travelled out the channel (runout distance $>140 \mathrm{~cm}$ ).

\section{Discussion}

\subsection{Granular fingers and ridges in experiments}

Our experiments showed that longitudinal ridges were formed through coalescence of margins of adjacent fingers (Fig. 8). The ridges were well-developed when the fingers were long and the central channels had drained sufficiently at final stages of emplacement to cause a notable difference in height with the ridges. Merging of margins could be incomplete and then led to ridges with two peak heights (Fig. 9). The most favourable conditions for the formation of ridges in experiments were met when the grain size ratio between the two components of the granular mixture was $\leq 1.9$ (i.e. mixture 1 , see Table 1 ) and the concentration of the large particles was $10-20 \mathrm{wt} \%$. At lower concentrations there were not enough coarse particles to promote efficient segregation and fingering. At higher concentrations, however, too many coarse particles accumulated at the flow front, which inhibited fingering and could even stop motion, and in this case the front of the deposit consisted of series of more or less defined lobes (as observed for mixtures with higher grain size ratios).

Series of separated fingers formed in mixtures with grain size ratios $\geq 2.1$. Our results suggest that these structures could arise at increasing coarse particles content when the size ratio increased, i.e. in mixture 3 (size ratio of 2.4) at $10 \mathrm{wt} \%$ and in mixture 4 (size ratio of 2.7 ) at $20 \mathrm{wt} \%$ (see Fig. 8). It appears that the formation of separated fingers required an optimal range of concentration of large particles for a given grain size ratio, similarly to the merged fingers, otherwise segregation was not sufficient (at low concentration) or the high amount of large particles at the flow front inhibited motion (at high concentration).

A fundamental difference between the separated and the merged fingers is the wavelength of the instabilities that led to the emergence of individual fingers at the flow front. We highlight that this wavelength cannot be predicted by the model of Pouliquen and Vallance (1999) and that Woodhouse et al. (2012) argued that the wavelength observed in their numerical simulations is dependent on the number of grid points used. Nevertheless, our data on the width of the fingers and on the distance between their axes (section 4.3) suggest that this wavelength may increase with the size ratio.
Note that the separated fingers are similar to the distal deposits of pumice or debris flows (Jessop et al., 2012; Kokelaar et al., 2014), which have well-defined levees bordering a central channel as well as a terminal frontal snout.

\subsection{Comparison with a natural case: The Tutupaca debris avalanche deposits}

We now compare our experimental results with observations made on natural debris avalanche deposits. We stress that the experiments allowed us to investigate the main factors controlling granular fingering in a configuration that represented an ideal simple case compared to natural systems. First, a high constant slope angle of $31^{\circ}$ was required in the models to generate slow granular flows from a steady release of material initially at rest, whereas in nature high flow velocity and inertia allow for propagation at much lower slopes angles. Also, topographic irregularities such as break in slopes occurring frequently in nature may alter significantly the flow dynamics (see Sulpizio et al., 2016). Second, granular fingering in poly-disperse natural materials could behave differently to the experimental bi-dispersed mixtures. Hence, although the general trends of development of granular fingering observed in the experiments may be extrapolated to natural systems, we stress that only qualitative implications of the experimental results can be discussed at this stage. In other words, the critical grain size ratios and coarse particle contents that promoted granular fingering in the experiments might have different values in nature.

We consider the Tutupaca volcano located in southern Peru, which we investigated recently (Samaniego et al., 2015; Valderrama et al., 2016). The last historical ( $218 \pm 14 \mathrm{aBP}$ ) eruption of Tutupaca generated a large sector collapse that triggered a debris avalanche and an associated pyroclastic eruption (Samaniego et al., 2015). The debris avalanche deposits are characterized by two distinct units: Unit 1 containing a large amount of hydrothermally altered material that mostly belongs to an older basal edifice, and Unit 2 consisting of fresh dacitic rocks from the youngest dome complex. Interestingly, the debris avalanche deposits have different surface morphologies, including longitudinal ridges that border depressions and distal surface frontal lobes that are present in all but the proximal areas covered by hummocks (Fig. 11). 


\section{Coarse particles concentration}
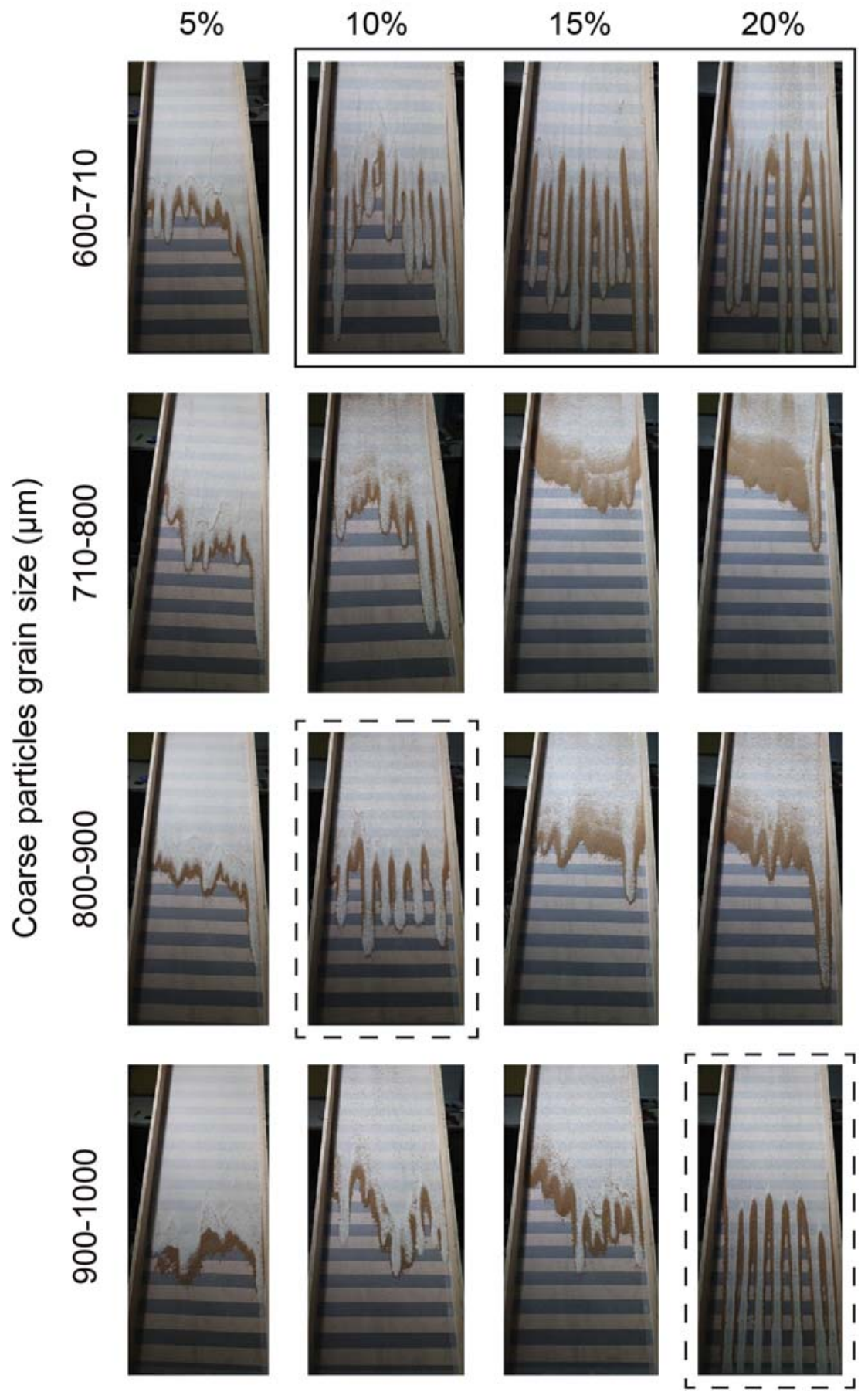

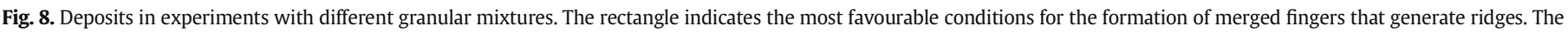
dashed rectangles point out well-developed separated fingers.

The analysis made by Valderrama et al. (2016) on $>300$ ridges revealed that these are $20-500-\mathrm{m}$ long (mean of $\sim 100 \mathrm{~m}$ ) and 10-30-m wide, and their top is $1-5 \mathrm{~m}$ above the depressions. The distance between the top of the ridges is $10-60 \mathrm{~m}$ (mean of $\sim 30 \mathrm{~m}$ ) and it increases with the travel distance as the ridges fan slightly outward. A key observation is that the ridges have coarser cores and finer troughs, which suggests grain size segregation during emplacement of the debris avalanche. Considering these structural and granulometric data Valderrama et al. (2016) argued that the ridges were formed through granular fingering and resulted from merging of lateral margins of fingers, and they became morphologically distinct when the central channels of the fingers drained at final stages of emplacement to form the depressions. Valderrama et al. (2016) concluded that these parts of the debris avalanche behaved like a granular flow, while the hummocky parts slid en-masse. Our new experimental data further support this conclusion and also give more insights into the granular behaviour of the Tutupaca debris avalanche.

Direct comparison between the Tutupaca debris avalanche and the experiments is not straightforward owing to the differences between the two systems mentioned above. Our experimental results, however, suggest that polydispersity is not required to promote granular fingering and ridges, and that the main control factor is rather the 

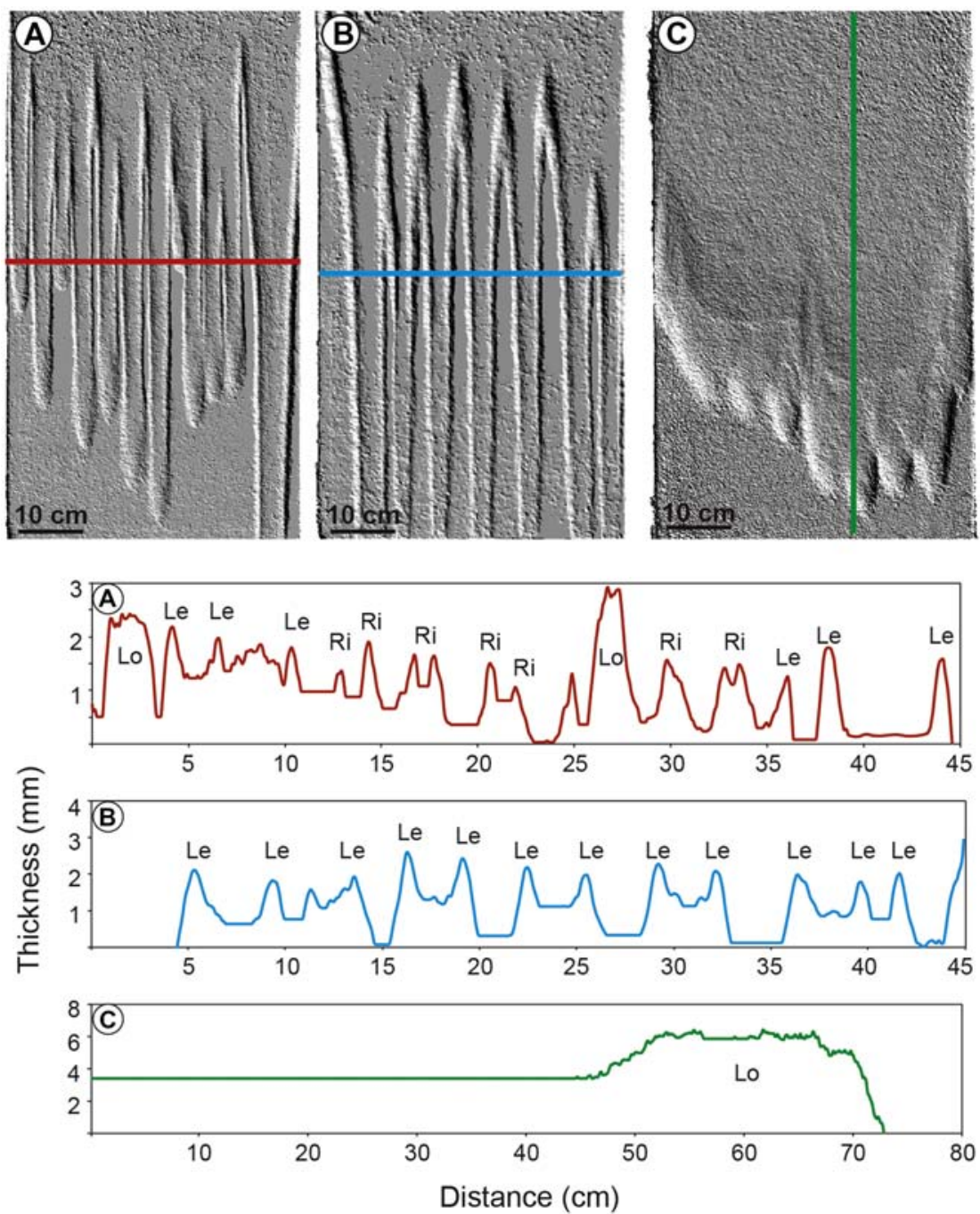

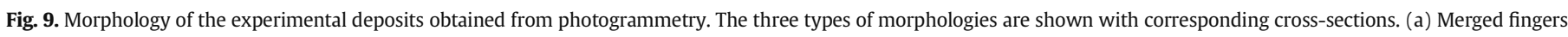

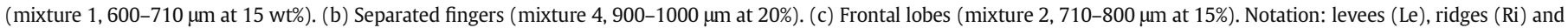
lobes (Lo).

presence of large particles at optimal concentrations (notice that particle angularity has only a second-order effect on fingering, cf. Pouliquen et al., 1997). The zone A in Fig. 11 shows a $1 \times 2 \mathrm{~km}$ area of the Tutupaca debris avalanche deposits with distinct subparallel ridges, at a distance of 4-5 km north of the amphitheatre. These ridges resemble those formed in experiments where coarse-rich margins of granular fingers coalesced. In nature, the varying underlying topography of the substrate on which the avalanche propagated as well as the possibility of the granular mass to spread radially led to non rectilinear ridges, in contrast to the simple configuration of the experiments. The distal zone B in Fig. 11 shows another area at about $6 \mathrm{~km}$ north-west of the amphitheatre, with a series of structures that can be interpreted as superposed frozen flow pulses that form frontal lobes. These structures are very similar to those in our experiments where granular fingering could not develop because of accumulation of coarse particles at flow front. The concentration of large blocks at front of the Tutupaca debris avalanche may have caused the lobes observed in the field.

\section{Conclusion}

Our experiments, which involved larger ranges of size ratio and of coarse particles content compared to earlier studies, were used to explore granular fingering. They revealed three distinct morphologies of deposits of flows of bi-disperse mixtures that experienced particle size segregation: joint fingers, separated fingers and frontal lobes, the latter being poorly developed fingers. Separated fingers were analogues of pumice flow deposits with lateral levees bordering a central, less elevated channel. Joint fingers were created at low size ratio $(\leq 1.9)$ and moderate coarse particle content (10-20 wt\%) and they led to the formation of longitudinal ridges, which are the core theme of our study (note that joint fingers and ridges in nature could occur at size ratios and coarse particle contents different than in experiments). In contrast, separated fingers and lobes formed at higher size ratios and/or coarse particle contents. The factors controlling the wavelength of the flow front instabilities, which sets the width of the fingers and hence the distance between the ridges, remain an open issue. Our results, however, suggest that this wavelength may increase with the coarse particle content. Though the experiments involved bi-disperse granular mixtures they were able to reproduce deposit structures formed from poly-disperse flows in nature, which suggests that large particles at optimal content is the key parameter for promoting fingering.

This experimental study shows that ridges can form as a consequence of granular fingering, which itself is caused primarily by particle size segregation. The ridges arise because of coalescence of coarse-rich lateral margins of joint fingers of nearly constant width and which drain at late emplacement stages. Therefore ridges are well-defined topographic highs spaced regularly. The main implication of the presence of ridges in deposits is that the parent debris avalanches behaved as 

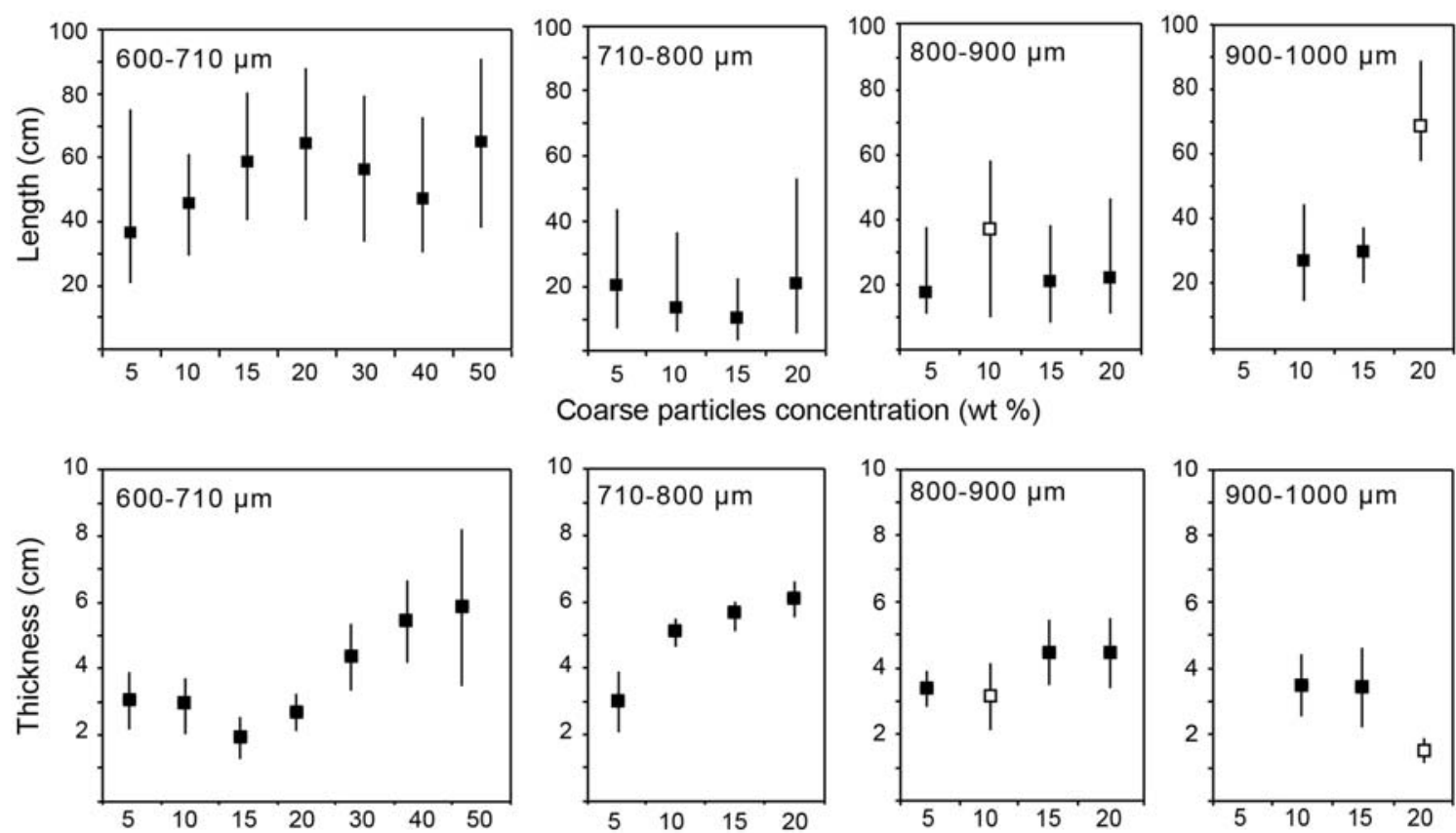

Coarse particles concentration (wt \%)
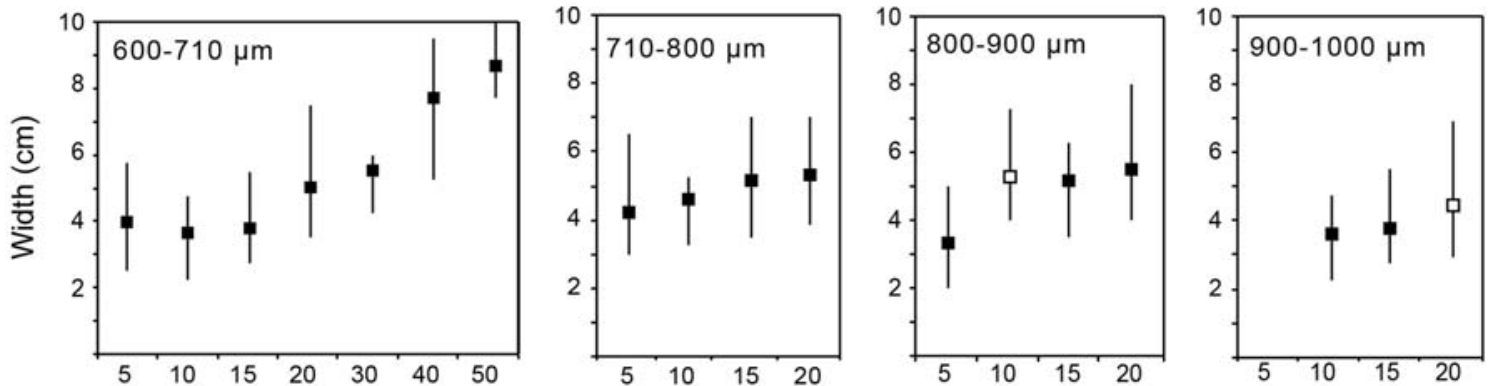

Coarse particles concentration (wt \%)
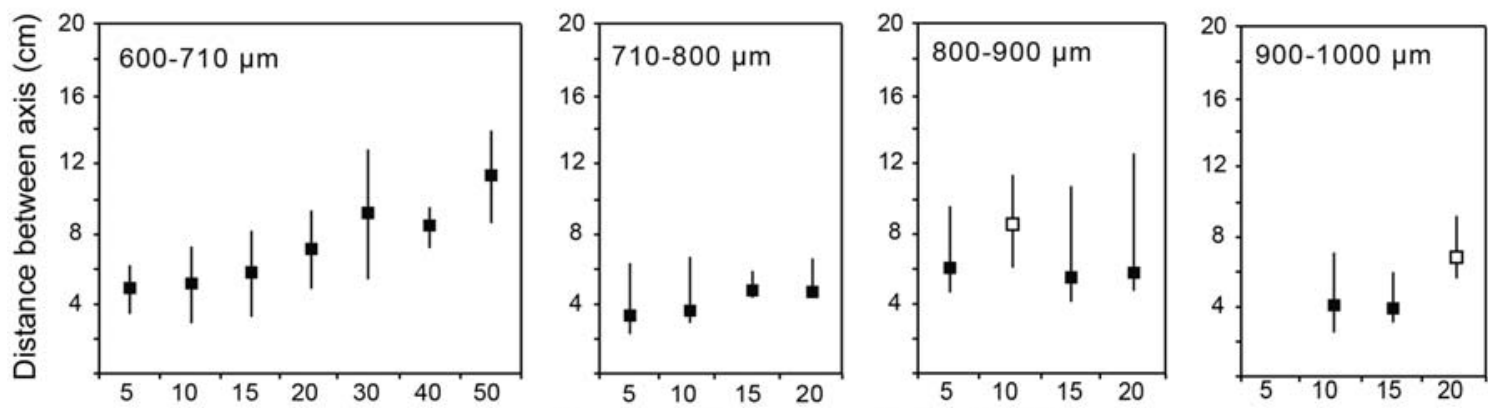

Coarse particles concentration (wt \%)

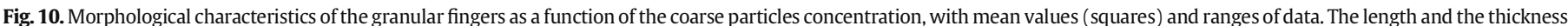

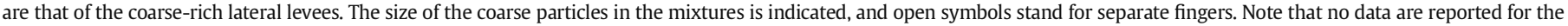
mixture with $5 \mathrm{wt} \%$ of $900-1000 \mu \mathrm{m}$ coarse particles because no measurable structures were formed.

granular flows, which adds to a commonly accepted model of emplacement by sliding of a coherent mass (see Shea and van Wyk de Vries, 2008, and references therein). The Tutupaca debris avalanche deposits suggest that both the granular flow and block sliding mechanisms can coexist during a given collapse event and lead to distinct surface morphologies. In this context the granular flow mechanism, favoured by high fragmentation of the collapsing material, may become dominant with the travel distance and therefore could promote granular flow indicated by increasing amounts of ridges. The absence of ridges in some deposits may be explained either by the dominance of sliding over flow and of the lack of material disaggregation, or grain size distributions not suitable for granular fingering.

\section{Acknowledgment}

This work is part of a collaborative programme between the Peruvian Instituto Geológico, Minero y Metalúrgico (INGEMMET) and the French Institut de Recherche pour le Développement (IRD). It was partially founded by IRD through a PhD grant awarded to P. Valderrama. This research was also supported by the French Government Laboratory 

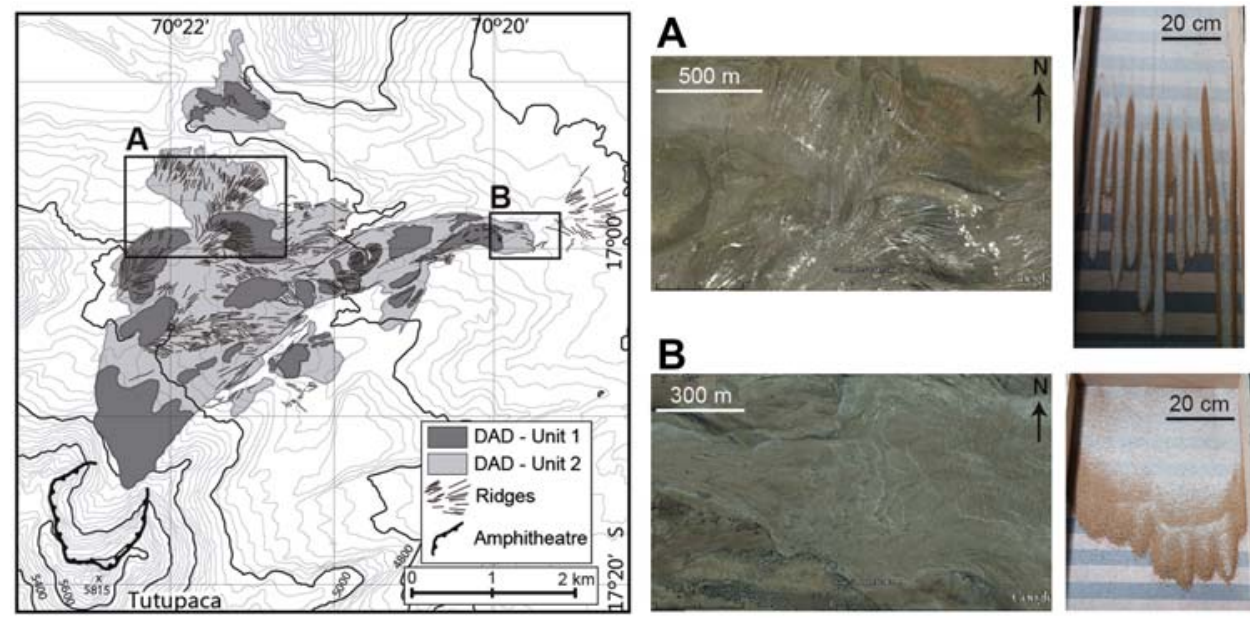

\section{B}
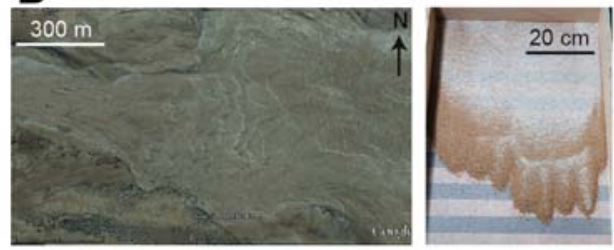

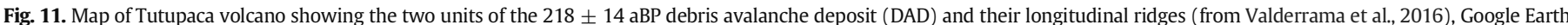

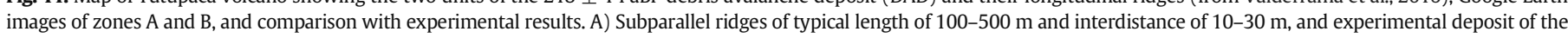

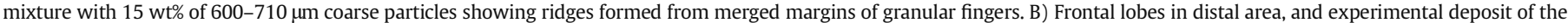
mixture with 15 wt\% of $710-800 \mu \mathrm{m}$ coarse particles showing frontal lobes.

of Excellence initiative no ANR-10-LABX-0006, the Région Auvergne and the European Regional Development Fund. This is Laboratory of Excellence ClerVolc contribution no 278. We thank Domenico Doronzo for useful comments.

\section{References}

Belousov, A., Belousova, M., Voight, B., 1999. Multiple edifice failures, debris avalanches and associated eruptions in the Holocene history of Shiveluch volcano, Kamchatka, Russia. Bull. Volcanol. 61:324-342. https://doi.org/10.1007/s004450050300.

Clavero, J.E., Sparks, R.S.J., Huppert, H.E., Dade, W.B., 2002. Geological constraints on the emplacement mechanism of the Parinacota debris avalanche, northern Chile. Bull. Volcanol. 64, 40-54.

Dufresne, A., Davies, T.R., 2009. Longitudinal ridges in mass movement deposits. Geomorphology 105:171-181. https://doi.org/10.1016/j.geomorph.2008.09.009.

Dufresne, A., Bosmeier, A., Prager, C., 2016. Sedimentology of rock avalanche deposits case study and review. Earth Sci. Rev. 163, 234-259.

Gray, J.M.N.T., Kokelaar, B.P., 2010. Large particle segregation, transport and accumulation in granular free-surface flows. J. Fluid Mech. 652:105-137. https://doi.org/10.1017/ S002211201000011X.

Gray, J.M.N.T., Gajjara, P., Kokelaar, P., 2015. Particle-size segregation in dense granular avalanches. C.R. Phys. 16:73-85. https://doi.org/10.1016/j.crhy.2015.1001.1004.

Jessop, D.E., Kelfoun, K., Labazuy, P., Mangeney, A., Roche, O., Tilliere, J.-L., Trouillete, M., Thibault, G., 2012. LiDAR derived morphology of the 1993 Lascar pyroclastic flow deposits, and implication for flow dynamics and rheology. J. Volcanol. Geotherm. Res. 245-246:81-97. https://doi.org/10.1016/j.jvolgeores.2012.06.030.

Johnson, C.G., Kokelaar, B.P., Iverson, R.M., Logan, M., La Husen, R.G., Gray, J.M.N.T., 2012. Grain-size segregation and levee formation in geophysical mass flows. J. Geophys. Res. 117, F01032. https://doi.org/10.01029/02011JF002185.

Kokelaar, B.P., Graham, R.L., Gray, J.M.N.T., Vallance, J.W., 2014. Fine-grained linings of leveed channels facilitate runout of granular flows. Earth Planet. Sci. Lett. 385:172-180. https://doi.org/10.1016/j.epsl.2013.10.043.

Luchitta, B.K.A., 1978. Large landslide on Mars. Geol. Soc. Am. Bull. 89, 1601-1609.

Malloggi, F., Lanuza, J., Andreotti, B., Clément, E., 2006. Erosion waves: transverse instabilities and fingering. Europhys. Lett. 75 (5):825-831. https://doi.org/10.1209/epl/ i2006-10174-10179.
Paguican, E.M.R., van Wyk de Vries, B., Lagmay, M.F., 2012. Hummocks: how they form and how they evolve in rockslide-debris avalanches. Landslides 11:67-80. https:// doi.org/10.1007/s10346-012-0368-y.

Pouliquen, O., Vallance, J.W., 1999. Segregation induced instabilities of granular fronts Chaos 9:621-630. https://doi.org/10.1063/1.166435.

Pouliquen, O., Delour, J., Savage, S.B., 1997. Fingering in granular flows. Nature 386 816-817.

Samaniego, P., Valderrama, P., Mariño, J., van Wyk de Vries, B., Roche, O., Manrique, N., Chédeville, C., Liorzou, C., Fidel, L., Malnatti, J., 2015. The historical (218 $+14 \mathrm{aBP})$ explosive eruption of Tutupaca volcano (Southern Peru). Bull. Volcanol. 77:51. https:// doi.org/10.1007/s00445-015-0937-8.

Shea T van Wyk de Vries, B, 2008. Structural analysis and analogue modeling of the kinematics and dynamics of rockslide avalanches. Geosphere 4:657-686. https:// doi.org/10.1130/GES00131.00131.

Smith, M.W., Carrivick, J.L., Quincey, D.J., 2016. Structure from motion photogrammetry in physical geography. Prog. Phys. Geogr. 40:247-275. https://doi.org/10.1177/ 0309133315615805.

Sulpizio, R., Castioni, D., Rodriguez-Sedano, L.A., Sarocchi, D., Lucchi, F., 2016. The influence of slope-angle ratio on the dynamics of granular flows: insights from laboratory experiments. Bull. Volcanol. 78:77. https://doi.org/10.1007/s00445-00016-0106900445.

Valderrama, P., Roche, O., Samaniego, P., van Wyk de Vries, B., Bernard, K., Mariño, J., 2016 Dynamic implications of ridges on a debris avalanche deposit at Tutupaca volcano (southern Peru). Bull. Volcanol. 78:14. https://doi.org/10.1007/s00445-016-1011-X.

Woodhouse, M.J., Thornton, A.R., Johnson, C.G., Kokelaar, B.P., Gray, J.M.N.T., 2012 Segregation-induced fingering instabilities in granular free-surface flows. J. Fluid Mech. 709, 543-580.

van Wyk de Vries, B., Self, S., Francis, P., Keszthelyi, L., 2001. A gravitational spreading origin for the Socompa debris avalanche. J. Volcanol. Geotherm. Res. 105:225-247. https://doi.org/10.1016/S0377-0273(00)00252-3.

van Wyk de Vries, B., Davies, T., 2015. Landslides, debris avalanches and volcanic gravitational deformation. In: Sigurdsson, H., et al. (Eds.), Encyclopedia of Volcanoes, 2nd edition Elsevier, pp. 665-685. 